\title{
The Effect of Race QCCJ of Puccinia graminis f. sp. tritici on Yield and Quality in Barley
} R. Dill-Macky, Assistant Professor, Department of Plant Pathology, University of Minnesota; and A. P. Roelfs, Re-
search Plant Pathologist, Cereal Disease Laboratory, USDA-Agricultural Research Service, University of Minne-
sota, St. Paul 55108

\begin{abstract}
Dill-Macky, R., and Roelfs, A. P. 1998. The effect of race QCCJ of Puccinia graminis f. sp. tritici on yield and quality in barley. Plant Dis. 82:674-678.

The progress of epidemics of race QCCJ of Puccinia graminis f. sp. tritici was examined in field plots of the barley cultivars Robust, Excel, Stander, Azure, Stark, Larker, Bonanza, and Steptoe. In addition, a potential source of resistance (cv. Diamond), and a susceptible line (ND11075) were included. Rust-free treatments were maintained to provide comparisons of grain yield and quality. Barleys with Rpgl, which confers resistance to races of $P$. graminis $\mathrm{f}$. sp. tritici other than Pgt-QCCJ, were generally more resistant than cultivars or lines that lacked this gene. However the severity of losses indicated that under high disease pressure the resistance conferred by Rpg1 would not be effective. Yield reductions of up to $29 \%$ were recorded and were generally associated with reduced grain size and weight. The continued presence of Pgt-QCCJ as a component of the P. graminis population in the United States, since it was first detected in 1989, indicates that $P g t$-QCCJ remains a threat to commercial barley production.
\end{abstract}

Additional keywords: Hordeum vulgare, stem rust

Since the release of Kindred in 1942, barley cultivars released to growers in the northern Great Plains of the United States and Canada have been presumed resistant to stem rust caused by Puccinia graminis $\mathrm{f}$. sp. tritici (24). This resistance has been conferred by a single gene, Rpgl (T gene) $(8,13,21,24)$. Prior to the deployment of Rpg1, P. graminis f. sp. tritici had caused a number of severe epidemics in barley resulting in devastating yield losses (23), although these epidemics were never as spectacular as epidemics reported in wheat crops (24).

In 1989, a new race of $P$. graminis f. sp. tritici, designated Pgt-QCCJ, was found in the Great Plains of the Unites States (14). $P g t$-QCCJ was isolated most frequently from barley (Hordeum vulgare L.) and

Corresponding author: R. Dill-Macky

E-mail: ruthdm@puccini.crl.umn.edu

Published as paper No. 981220039 of the contribution series of the Minnesota Agricultural Experiment Station based on research conducted under Project 22-52, supported by the American Malting Barley Association.

Names are necessary to report factually on available data: however, the USDA neither guarantees nor warrants the standard of the product, and the use of the name by the USDA implies no approval of the product to the exclusion of others that may also be suitable.

Accepted for publication 9 March 1998.

Publication no. D-1998-0413-02R

(C) 1998 The American Phytopathological Society wild barley (H. jubatum L.) in 1989, suggesting that this race was primarily a pathogen of Hordeum spp. In 1990, PgtQCCJ was reported in winter barley plots in western Kansas, and was widespread in commercial fields in southeastern North Dakota and west-central Minnesota. Reported severities ranged from trace to $60 \%$, making this the most widespread and severe epidemic of stem rust in barley in the Upper Midwest since the 1930s (19). The level of stem rust observed in commercial barley fields in 1990 suggested that the resistance provided by Rpgl was ineffective against Pgt-QCCJ. In 1990 and 1991, Pgt-QCCJ was also widely distributed in winter wheat across Kansas and eastern Colorado. While most plots were lightly rusted, plots of the cultivars 2157 and Quantum 542 were reported with severities of 20 to $50 \%$ in north-central and northwestern Kansas in 1991 (14). Pgt-QCCJ became a major component of the $P$. graminis f. sp. tritici population, constituting $19,68,68,50,22,26$, and $31 \%$ of $P$. graminis f. sp. tritici isolates collected from wheat and barley in United States Department of Agriculture (USDA) rust surveys from 1989 through 1995, respectively $(9,10,14-18)$. Collections of $P$. graminis $\mathrm{f}$. sp. tritici from $H$. vulgare and $H$. jubatum indicate that Pgt-QCCJ dominates on these hosts; Pgt-QCCJ constituted 89, 56, 90, and 93\% of isolates from 1992 through 1995 , respectively $(9,10,17,18)$. In 1996, Pgt-QCCJ was a smaller component of the $P$. graminis f. sp. tritici population, being $1 \%$ of isolates from wheat and $14 \%$ of isolates from cultivated barley. The reduction of $P g t$-QCCJ likely reflects a smaller $P$. graminis population and reduced planting of winter wheat cultivars in Kansas susceptible to this race (D. L. Long, personal communication).

Rpg1 may still confer some degree of resistance to race QCCJ because stem rust severities have been low to moderate, and yield losses light, in barley cultivars carrying the gene during the five seasons of 1991 to 1995. Inoculum of Pgt-QCCJ most likely comes from southern plantings of susceptible winter wheats. Rapid action taken after the appearance of Pgt-QCCJ to reduce the area planted to susceptible cultivars may have averted the buildup of inoculum levels necessary for generating severe stem rust epidemics on barley in the northern Great Plains.

Field experiments were conducted on the Minnesota Agricultural Experiment Station at Rosemount in 1993 and 1994 to examine the development of epidemics of $P g t$-QCCJ in barley and to evaluate differences in resistance to this race of stem rust in commercial cultivars with respect to Rpg1.

\section{MATERIALS AND METHODS}

Ten barley cultivars were tested. Robust, Excel, and Stander are six-rowed malting cultivars produced by the Minnesota breeding program which together accounted for 96 and $95 \%$ of the commercial barley planted in Minnesota in 1993 and 1994, respectively. These same cultivars comprised 73 and $83 \%$ of the North Dakota crop in those years. Azure, a sixrowed malting barley, and Stark, a tworowed malting barley, were developed in breeding programs at North Dakota State University. Together, these five barley lines account for over $80 \%$ of the total area planted to barley in Minnesota in the 1989 to 1994 seasons, and over $62 \%$ of the area in North Dakota, the largest barley-producing state in the Midwest. Larker, a malting cultivar released in 1950, was included in the study to enable a comparison between older and more-recently released cultivars with the Rpg1 resistance. Bonanza, a six-rowed type developed in Manitoba, Canada, is adapted to the majority of areas where barley stem rust research is currently being pursued. It was intended that the inclusion of Bonanza would facilitate the comparison of results 
conducted by other rust workers in the United States and Canada. Steptoe was included as a susceptible check, and is a sixrowed barley developed in the state of Washington, well-adapted to Minnesota but lacking any reported genes for stem rust resistance (11). Diamond, a six-rowed cultivar released from Alberta, Canada, had been identified as a possible source of resistance to race QCCJ $(4,25)$. ND11075 was identified as highly susceptible to stem rust (B. J. Steffenson, personal communication).

A single isolate of race QCCJ of $P$. graminis f. sp. tritici (20) was used. The isolate was increased on seedlings of Baart wheat. Seedlings were sown in flats in the greenhouse and inoculated about 1 week after planting with urediniospores suspended in light mineral oil (Soltrol 170, Phillips Petroleum Co., Bartlesville, OK). Inoculated plants were placed in a dew chamber $\left(18^{\circ} \mathrm{C}\right)$ overnight to promote infection. The plants were isolated in a greenhouse compartment $\left(20\right.$ to $\left.22^{\circ} \mathrm{C}\right)$ until spore collection. About 14 days after inoculation, urediniospores were collected with a cyclone spore collector. Urediniospores were sieved to remove debris, dried in a desiccator to $20 \%$ relative humidity, and stored in cryovials in an ultra-low temperature freezer $\left(-80^{\circ} \mathrm{C}\right)$ until required.

1993 experiment. Four replicates of rusted and rust-free plots of each of the 10 barley lines, arranged in a randomized split block design (main plot = rust treatment; subplot $=$ cultivar), were planted at the University of Minnesota Agricultural Experiment Station in Rosemount, Minnesota, on 14 May. Each 10-row plot measured 3.7 by $1.8 \mathrm{~m}$. Plots were seeded with $100 \mathrm{~kg}$ viable seeds/ha, a seeding rate similar to that used in commercial production. Individual plots were surrounded by at least $2.5 \mathrm{~m}$ planted with a mixture (1:1) of Robust and Excel barleys, which acted as spreaders. The spreaders were planted 21 days prior to the plots. A border strip (1.8 m width) of Baart wheat was planted outside of the trial to help initiate the epidemic within the spreaders and was seeded along with the plots on 14 May. Both plots and spreaders were planted using a standard row spacing of $18 \mathrm{~cm}$.

The stem rust epidemics were initiated by inoculating the strips of Baart with PgtQCCJ when the majority of spreader plants were at Zadok's growth stage (gs) 22 and Robust plots were at gs 14 (26). The Baart wheat border was sprayed with a suspension of urediniospores (1 $\mathrm{g}$ urediniospores/liter deionized water) at approximately $4 \mathrm{ml} / \mathrm{m}^{2}$. Two days later, Baart culms at $0.5-\mathrm{m}$ intervals in the middle row of the strips were inoculated with $0.3 \mathrm{ml}$ of a suspension of urediniospores $(0.2 \mathrm{~g}$ urediniospores in $100 \mathrm{ml}$ deionized water) using an automatic pipetting outfit (B-D Cornwall; Becton, Dickinson and Co., Rutherford, NJ) and hypodermic syringe. In addition to the inoculation of the Baart, the barley spreaders surrounding the rusted plots were inoculated on 17,20 , and 25 June as the flag leaf sheaths extended and emergence of the inflorescence progressed (spreaders gs 41 to 55; Robust plots gs 22 to 31 ). Inoculations were made by the application of approximately 2.25 liters spore suspension (approximately $0.73 \mathrm{~g}$ urediniospores/liter light mineral oil) to the spreaders using a backpack sprayer. Reference plots were maintained virtually free of rust by a single application of propiconazole (122 $\mathrm{g}$ a.i./ha) on 9 July.

Broadleaf weeds were controlled by a single application of bromoxynil (585 $\mathrm{g}$ a.i./ha) and acetic acid (4-chloro-2 methylphenoxy; $805 \mathrm{~g}$ a.i./ha) on 11 June. Powdery mildew was detected in the trial at gs 32. Powdery mildew levels diminished prior to the application of propiconazole, and by gs 75 mildew was inconspicuous in both the rusted and rust-free treatments.

Rust development was assessed seven times at 3- to 4-day intervals after the initial appearance of symptoms in the plots. Twenty arbitrarily selected culms from each plot were assessed visually to determine the incidence and severity of rust. Rust severity was assessed using the key developed by James (5), where the percentage of infection noted represents the actual area covered by the pustules. Rust incidence was recorded as the proportion of culms with visible uredinia.

At maturity, 100 heads were hand-harvested from plots and used in the determination of 100 -head weights, 1,000-grain weights, and grain-size distribution. Handharvested heads were threshed using a belt thresher. The remainder of each plot was mechanically harvested for grain yield. Yield data for both 100-head samples and machine-harvested plots were combined in the determination of total plot yields. The average weight of two counts of 200 grains from each sample was used to calculate 1,000-grain weights. Percentage of plump grain (above $2.4 \mathrm{~mm}$ in diameter), medium-sized grain (2 to $2.4 \mathrm{~mm}$ in diameter), and screenings (less than $2 \mathrm{~mm}$ in diameter) was determined by shaking $50 \mathrm{~g}$ grain for 2 min through a series of screens with slits 2.4 and $2 \mathrm{~mm}$ wide.

All data were evaluated by analysis of variance. Where the $F$ ratio for treatments was significant $(P<0.05)$, differences among treatment means were tested using least significant differences.

1994 experiment. The experimental plots, planted on 31 May, were similar to those planted in 1993 with the following exceptions. Plots were seeded at $95 \mathrm{~kg}$ viable seeds/ha. Plots were surrounded by spreaders consisting of a mixture $(5: 2)$ of Robust and M88-6 barleys planted 27 days prior to the plots. M88-6 is a Minnesota breeding line identified as being highly susceptible to stem rust.

The stem rust epidemic was initiated by inoculating the Robust and M88-6 spread- ers surrounding the rusted plots with PgtQCCJ. The spreaders were inoculated on $19,21,22,24$, and 30 June and 1 July by the application of spore suspensions (approximately $0.86 \mathrm{~g}$ urediniospores/liter light mineral oil). Two liters of spore suspension was used for the first inoculation, and approximately 0.8 liter was used in the subsequent inoculations. The growth stage of the barley spreaders over this time ranged from flag leaf sheaths extending to complete emergence of the spike (gs 41 to 59) and the Robust barley plots from five leaves unfolded to flag leaf emerging (gs 15 to 37). Reference plots were maintained virtually free of rust by a single application of propiconazole (122 $\mathrm{g}$ a.i./ha) on 19 July. Broadleaf and grass weeds were controlled by a single application of bromoxynil (585 $\mathrm{g}$ a.i./ha) and diclofop-methyl (532 g a.i./ha)
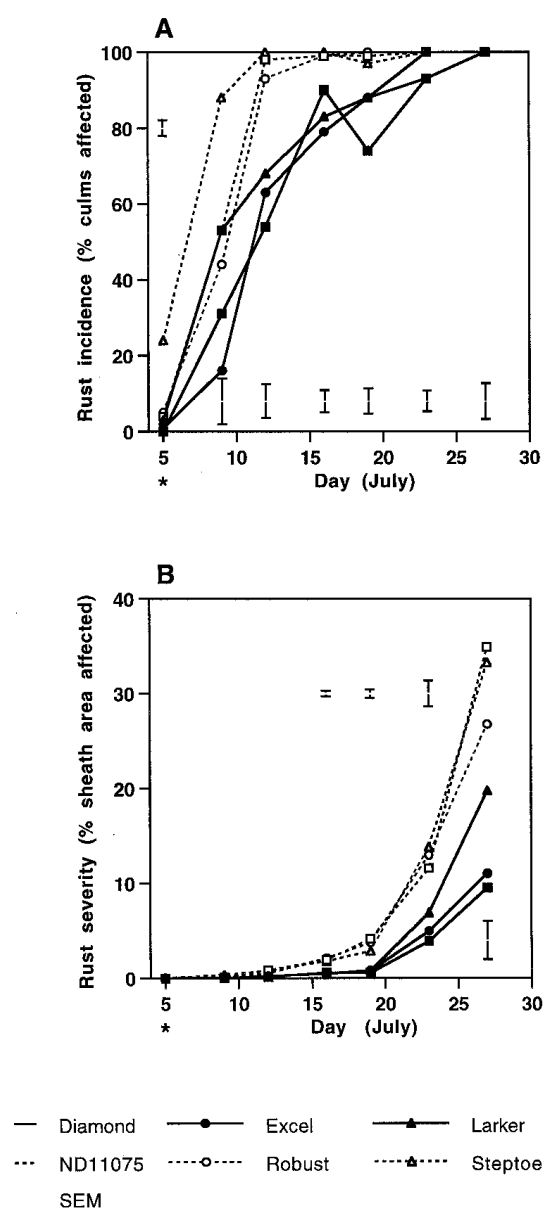

Fig. 1. Stem rust progress in barley cultivars inoculated with race QCCJ of Puccinia graminis f. sp. tritici in 1993. Disease progress recorded as (A) rust incidence (\% culms affected) and (B) rust severity (\% sheath area affected). Error bars indicate standard errors of means. Asterisks indicate the approximate date of anthesis (growth stage 65) for the barley cultivars. 
on 20 June, supplemented with handweeding at regular intervals.

At maturity, 200 heads were hand-harvested from plots and used in grain quality assessments, and the remainder of each plot was mechanically harvested.
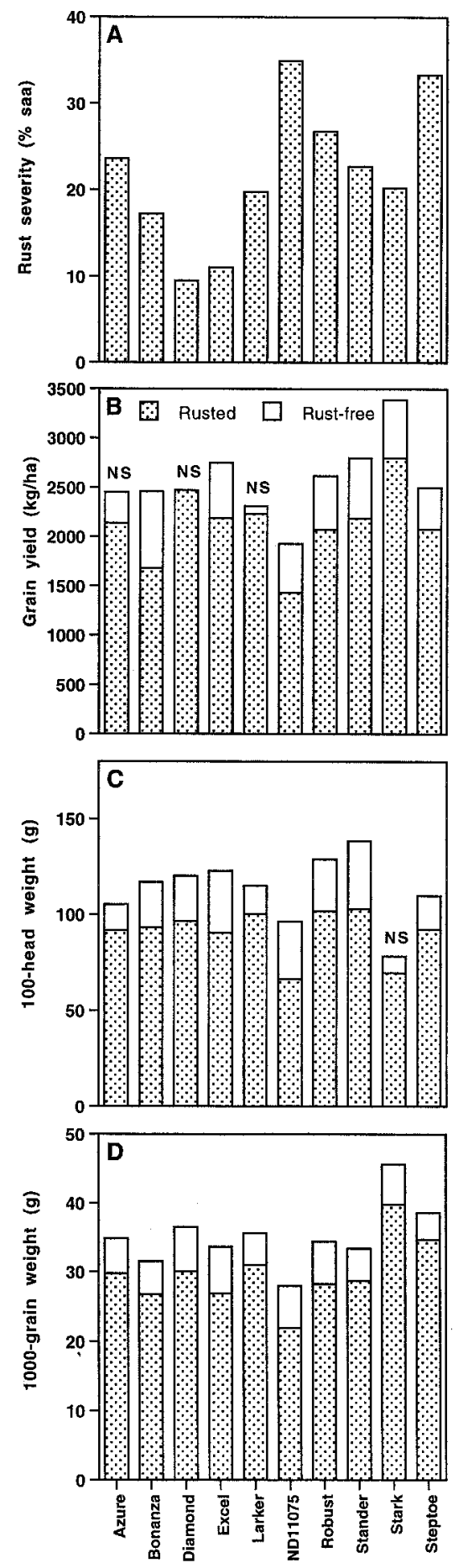

Fig. 2. (A) Rust severity (\% sheath area affected on 27 July), (B) grain yield (kg/ha), (C) 100-head weight (g), and (D) 1,000-grain weight $(\mathrm{g})$ for barley cultivars inoculated with race QCCJ of Puccinia graminis f. sp. tritici in 1993. "NS" on columns indicate that rusted and rust-free treatments are not significantly different $(P=0.05)$.

\section{RESULTS}

Rust samples were arbitrarily collected throughout the field sites in 1993 (32 collections) and 1994 (60 collections) at crop maturity. The collections were tested to determine if contamination of the epidemic by other races had occurred. In 1993, 25 collections were identified as Pgt-QCCJ, six as a mixture of Pgt-QCCJ and other races, and one collection was a race other than Pgt-QCCJ. In 1994, 58 collections were identified as $P g t$-QCCJ and two were identified as races other than $P g t$-QCCJ.

1993 experiment. Significant differences in the incidence and severity of stem rust were evident among barley cultivars at the initial assessment (5 July), 21 days after the initiation of epidemics by hypodermic inoculation (Fig. 1A, B). Stem rust developed rapidly in inoculated plots of susceptible cultivars. At the final assessment (27 July), the incidence of rust in inoculated plots had reached 100\% and severities ranged from $9.5 \%$ in Diamond to over 33\% in Steptoe and ND11075. The rust-free plots were largely protected by a single fungicide application, although stem rust was present as plants neared maturity. The severity of stem rust at the final disease assessment was below 5\% in all rust-free plots and the average rust severity was $0.5 \%$.

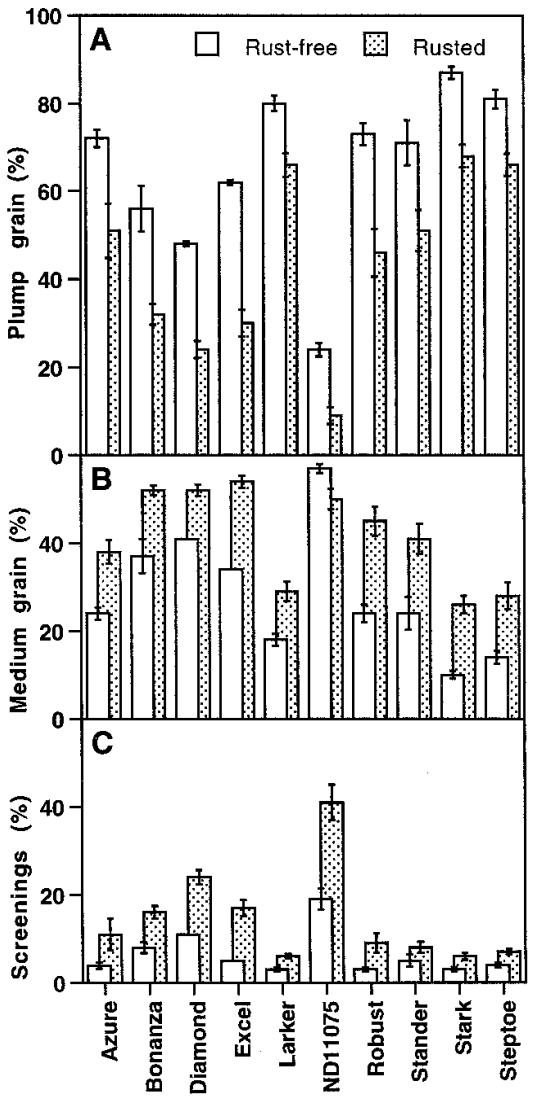

Fig. 3. (A) Plump grain, (B) medium-sized grain, and (C) screenings for barley cultivars inoculated with race QCCJ of Puccinia graminis f. sp. tritici in 1993. Error bars indicate standard errors of means.
Stem rust development was greatest in ND11075 and Steptoe, moderate in Robust, Azure, Stander, Stark, Larker, and Bonanza, and least in Excel and Diamond. Disease progress for six of these cultivars is depicted in Figure 1B. At the final disease assessment, plants in rust-free treatments were at soft- to hard-dough growth stages (gs 85 to 87 ); plants in rusted plots were at hard-dough or ripening where the caryopsis was difficult to divide (gs 87 to 91). Among the rusted treatments, Azure, Bonanza, Larker, ND11075, Stander, and Steptoe matured earlier than the other cultivars. The rust development likely hastened maturity, although the application of fungicide to the rust-free treatments may have delayed maturity in treated plots.

Grain yields of all cultivars tested except Diamond, Larker, and Azure were significantly reduced by stem rust, with losses ranging from 16 to $26 \%$ (Fig. 2A, B). The loss in grain yield from hand-harvested 100-head weights (averaging 19.6\%) closely matched the losses measured in the machine-harvested plots (averaging $17.9 \%$ ), with losses significant at $P<0.05$ in all cultivars except Stark. As a tworowed cultivar, Stark had a lower head weight than any of the six-rowed barleys, and this may have contributed to a lack of significance (Fig. 2C).

The 1,000-grain weights showed a trend similar to the 100 -head weight data with significant losses of 8 to $22 \%$ in all cultivars examined (Fig. 2C, D and Table 1). Variations in grain size, as indicated by an increased percentage of screenings, were similarly consistent with yield losses. Reduced yields of plump grain resulting from stem rust were reflected in an increased percentage of screenings (Fig. 3).

1994 experiment. Significant differences in the incidence and severity of stem rust were evident among barley cultivars at the initial assessment (11 July) in the 1994 experiment (Fig. 4). Rust incidence increased rapidly, with $50 \%$ incidence recorded in all barley cultivars, except Diamond, by gs 71. Rust incidence was greater for cultivars in 1994 than in 1993 at equivalent growth stages (Figs. 1 and 4). Severe epidemics developed in inoculated

Table 1. Coefficients of determination $\left(r^{2}\right)$ for correlations of reductions in 100-head weight and reductions in 1,000-grain weight, plump grain, and increases in screenings for 10 barley cultivars in 1993 and 1994

\begin{tabular}{cccc}
\hline & \multicolumn{3}{c}{ Coefficient of determination } \\
\cline { 2 - 4 } Year & $\begin{array}{c}\text { 1,000-grain } \\
\text { weight }^{\mathbf{a}}\end{array}$ & $\begin{array}{c}\text { Plump } \\
\text { grain }^{\mathbf{a}}\end{array}$ & Screenings $^{\mathbf{b}}$ \\
\hline 1993 & $0.74^{\mathrm{c}}$ & $\ldots$ & 0.53 \\
1994 & 0.68 & $0.42^{*}$ & 0.59 \\
\hline
\end{tabular}

a $\%$ reduction.

b $\%$ increase.

c Values significant at $P<0.01$, except if marked with an asterisk, which denotes significance at $P<0.05$. 
plots and the rust incidence in inoculated plots exceeded $95 \%$ by the fourth assessment (22 July; Fig. 4A).

Stem rust development was greater in 1994 than 1993, with terminal rust severities ranging from 12 to $55 \%$ in 1994 , compared to a range of 10 to $38 \%$ in 1993 (Figs. 1B and 4B). The relative ranking of barley cultivars was generally in agreement (Spearman's coefficient of rank correlation $=0.54$ ), with Diamond, Excel, and Larker having the lowest rust severities and Steptoe and ND11075 being among the most severely rusted lines in both years (Figs. 1B and 4B). While fungicide applications clearly reduced the development of rust in the rust-free plots in 1994, the incidence of stem rust was high (averaging $79 \%$ ) by the final assessment. Despite the appearance of rust in control plots, terminal rust severities stayed below 3\% in all plots treated with propiconazole.

Reductions in grain yields were significant $(P<0.05)$ in only three cultivars: Bonanza, Larker, and Robust (Fig. 5B).
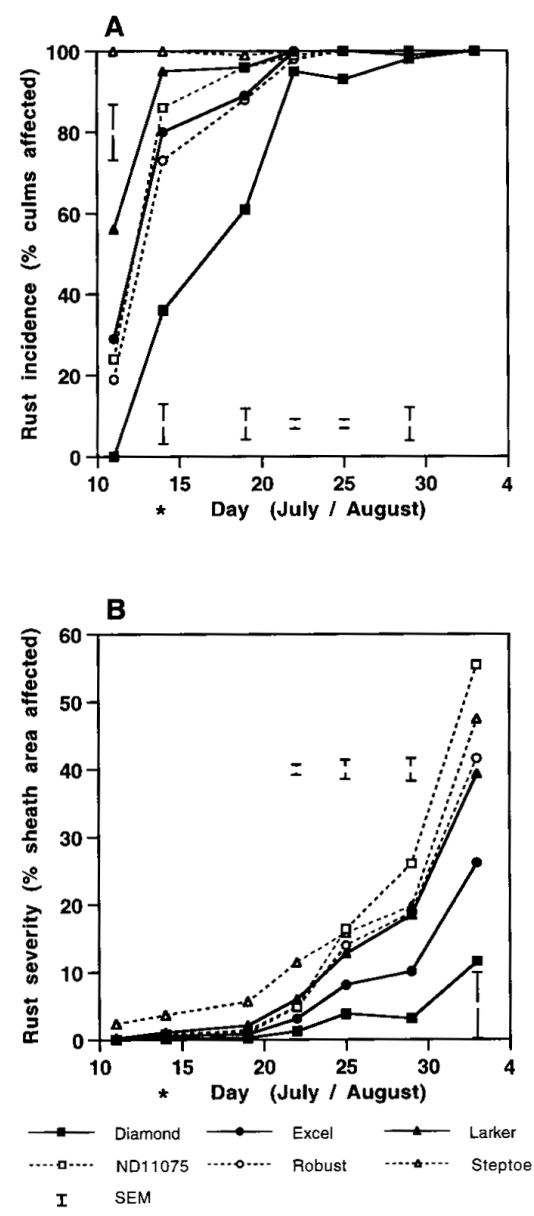

Fig. 4. Stem rust progress in barley cultivars inoculated with race QCCJ of Puccinia graminis f. sp. tritici in 1994. Disease progress recorded as (A) rust incidence (\% culms affected) and (B) rust severity (\% sheath area affected). Error bars indicate standard errors of means. Asterisks indicate the approximate date of anthesis (growth stage 65) for the barley cultivars.
The apparent lack of yield losses in the majority of cultivars may be partially attributed to losses associated with shattering in the field as rain prevented the timely harvest of plots. The rust-free plots may have been more prone to shattering, because these plants remained standing when the weakened plants in the rusted plots
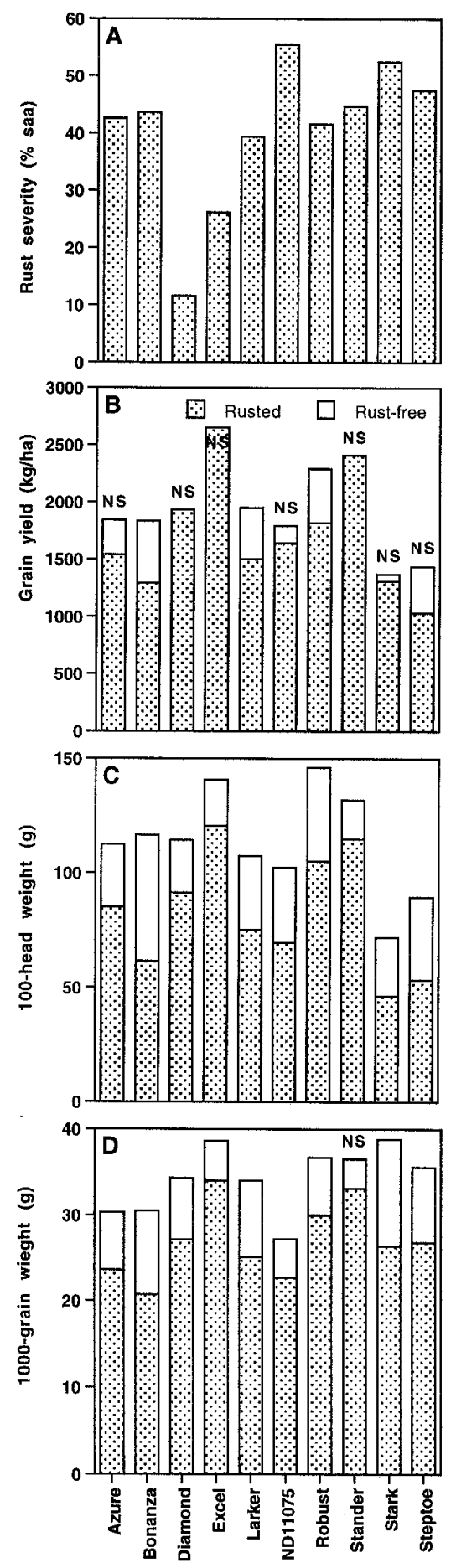

Fig. 5. (A) Rust severity (\% sheath area affected on 2 August), (B) grain yield (g), (C) 100-head weight (g), and (D) 1,000-grain weight $(\mathrm{g})$ for barley cultivars inoculated with race QCCJ of Puccinia graminis $\mathrm{f}$. sp. tritici in 1994. "NS" on columns indicate that rusted and rust-free treatments are not significantly different $(P=0.05)$. lodged and may thus have been protected. As yield losses were generally not significant, no attempt was made to correlate disease severity readings with yield losses. The 100-head data from hand-harvested material indicated greater losses (averaging $28.5 \%$ ) than the yield data from the machine harvesting (averaging 13.1\%). Significant reductions in 100-head weights were recorded for all cultivars, with losses ranging from around $12 \%$ in Stander and Excel to almost 50\% in Bonanza (Fig. 5C). Reductions in 1,000-grain weight were similar in magnitude and ranked cultivars in a similar order to the 100-head weight data (Fig. 5D, Spearman's coefficient of rank correlation $=0.79$ ). Reductions in plump grain and an increase in the percentage screenings paralleled losses in 100head weight and 1,000-grain weight, demonstrating that yield losses are largely due to reductions in grain size (Fig. 6, Table 1).

\section{DISCUSSION}

Epidemics of $P g t$-QCCJ were shown to develop rapidly in some Midwestern barley cultivars and reduced grain yield and quality. While it is apparent that some barley cultivars possess a degree of resistance to Pgt-QCCJ, none of the barley cultivars tested exhibited complete resistance. Bar-

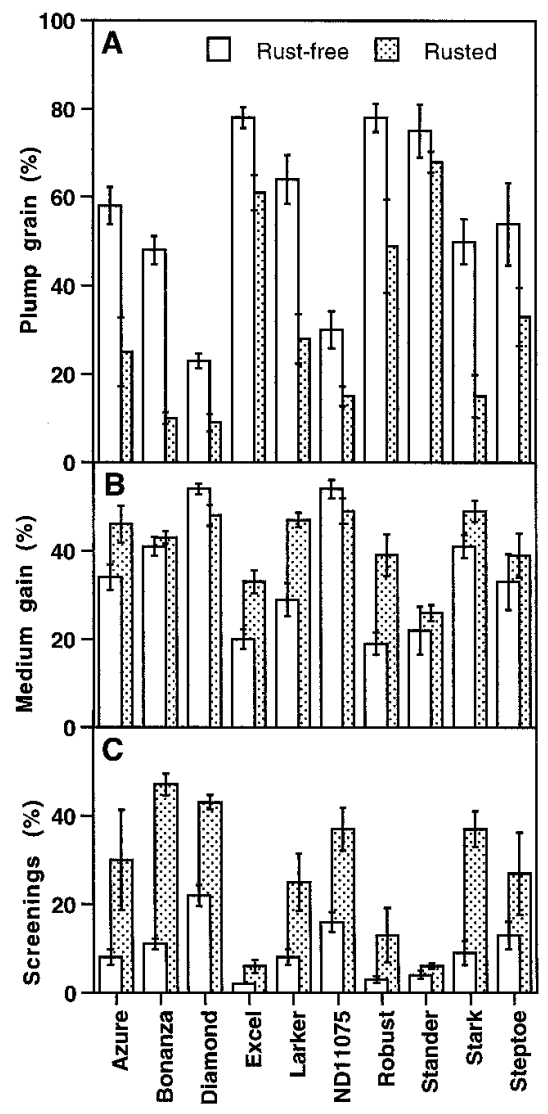

Fig. 6. (A) Plump grain, (B) medium-sized grain, and (C) screenings for barley cultivars inoculated with race QCCJ of Puccinia graminis f. sp. tritici in 1994. Error bars indicate standard errors of means. 
ley cultivars with Rpgl were generally more resistant than cultivars that lacked this gene; however, the yield losses in the 1993 study indicate that, under high disease pressure, resistance conferred by Rpg1 would not effectively protect commercial crops.

Larker, which was released in 1950 with resistance conferred by Rpgl, appears to be more resistant to Pgt-QCCJ than morerecently released cultivars. This suggests that minor genes that enhance the resistance conferred by Rpgl may have been lost in newer cultivars. The presence of minor genes has been reported in older cultivars. Lejeune (7) and Shands (22) both reported modification of the resistant reaction in Chevron by a genetic factor or factors of minor importance. Patterson (12) also found evidence for more than one locus conferring resistance in Valentine, a cultivar in which resistance to stem rust was conferred primarily by Rpgl.

The incomplete resistance present in some cultivars was effective in reducing rust development (Figs. 1 and 4). Differences in resistance were evident between closely related lines developed at the University of Minnesota. Excel had significantly lower rust severities than either Robust or Stander. Robust is a parent of Excel. Stander has both Robust and Excel in its pedigree. This suggests that the resistance in Excel came from one or more of the other parents in the cross (Cree, Bonanza, and Manker) and, further, that the resistance was lost in the development of Stander. As the resistance of Bonanza was less than Excel, one may also assume that the resistance of Excel came from Cree or Manker or from the effective combination of minor genes from more than one parent. The minor resistance gene or genes operating in Excel and Larker have not been identified.

Yield losses in these experiments can be largely attributed to the negative effect of stem rust on grain weight and size (Figs. 2, 3, 5, and 6). Comparable losses to stem rust in barley have been reported following infection with other races of $P$. graminis (3). Similarly, reductions in grain weight and grain size have been associated with stem rust of wheat (2) and barley leaf rust caused by $P$. hordei (6). The yields reported in this study are below the expected yield for barley grown in the Upper Midwest due to the late planting of plots as necessitated by the use of spreaders to promote disease development. In the Upper Midwest, late plantings of barley have lower yield potentials (27). Late-planted crops may also be exposed at earlier growth stages to inoculum generated in the southern states and thus run an increased risk of sustaining economic losses to $P$. graminis. Reductions in grain size adversely affect the quality of barley. Barley kernels of different sizes vary in malting behavior and produce malts with different properties (1); the small kernels from the rusted plots in this study were generally unsuitable for the production of malt.

This study demonstrates the potential for race $P g t$-QCCJ to seriously impact barley production in the United States and Canada. The epidemics in barley in the Upper Midwest in 1990 partially resulted from high levels of inoculum produced on susceptible winter wheats in Kansas. Prompt action was taken to remove the inoculum threatening commercial barley plantings in 1990. Stem rust-susceptible winter wheats, including the cultivar 2157, were withdrawn from the recommended cultivar lists in Kansas. At least one advanced line (Sumner) was dropped prior to its release as a result of its susceptibility to PgtQCCJ. Had these actions not been taken, continuing losses may well have ensued. The presence of $P g t$-QCCJ as a component of the $P$. graminis population in North America remains a concern to pathologists and plant breeders in the United States and Canada.

\section{ACKNOWLEDGMENTS}

We thank A. M. Elakkad, C. M. Schraut, J. L. Matheson, and the staff of the Rosemount Experiment Station for their valuable assistance; and D. C. Rasmusson and B. J. Steffenson for providing barley germplasm.

\section{LITERATURE CITED}

1. Berger, W. C., and La Burge, D. E. 1985. Malting and brewing quality. Pages 367-401 in: Barley. D. C. Rasmusson, ed. Agron. Ser. 26. Am. Soc. Agron./Crop Sci. Soc. Am./Soil Sci. Soc. Am., Madison, WI.

2. Calpouzos, L., Roelfs, A. P., Madson, M. E., Martin, F. B., Welsh, J. R., and Wilcoxson, R. D. 1976. A new model to measure yield losses caused by stem rust in spring wheat. Minn. Agric. Exp. Stn. Tech. Bull. 107:1-23.

3. Dill-Macky, R., Rees, R. G., and Platz, G. J. 1990. Stem rust epidemics and their effects on grain yield and quality in Australian barley cultivars. Aust. J. Agric. Res. 41:1057-1063.

4. Fox, S. L. 1993. Genetics and pathology involving stem rust resistance in barley. Ph.D. Thesis, University of Manitoba, Winnipeg, Canada.

5. James, W. C. 1971. An illustrated series of assessment keys for plant diseases, their preparation and usage. Can. Plant Dis. Surv. 51:39-65.

6. Johnson, D. A., and Wilcoxson, R. D. 1979. Yield losses of fast and slow rusting barleys infected with Puccinia hordei. Plant Dis. Rep. 63:764-768.

7. Lejeune, A. J. 1946. Correlated inheritance of stem rust reaction, nitrogen content of grain and kernel weight in a barley cross. Sci. Agric. 26:198-211.

8. Lejeune, A. J. 1951. The story of Kindred (L) barley. Barley Improvement Conference, Minneapolis, MN.

9. McVey, D. V., Long, D. L., and Roberts, J. J. 1996. Races of Puccinia graminis in the United States during 1994. Plant Dis. 80:8589.

10. McVey, D. V., Long, D. L., and Roberts, J. J. 1996. Races of Puccinia graminis in the United States during 1995. Plant Dis. 81:306310.

11. Nilan, R. A., Morrison, K. J., and Muir, C. 1974. Steptoe barley. Wash. State Univ. Coop. Ext. Serv. Ext. Circ. 392.

12. Patterson, F. L. 1950. Adult plant and seedling reactions of barley varieties and hybrids to three races of Puccinia graminis tritici. Ph.D. thesis. University of Wisconsin, Madison.

13. Powers, L., and Hines, L. 1933. Inheritance of reaction to stem rust and barbing awns in barley crosses. J. Agric. Res. 46:1121-1129.

14. Roelfs, A. P., Casper, D. H., Long, D. L., and Roberts, J. J. 1991. Races of Puccinia graminis in the United States in 1989. Plant Dis. 75:1127-1130.

15. Roelfs, A. P., Long, D. L., and Roberts, J. J. 1993. Races of Puccinia graminis in the United States during 1990. Plant Dis. 77:125128.

16. Roelfs, A. P., Long, D. L., and Roberts, J. J. 1993. Races of Puccinia graminis in the United States during 1991. Plant Dis. 77:129132.

17. Roelfs, A. P., Long, D. L., and Roberts, J. J. 1993. Races of Puccinia graminis in the United States during 1992. Plant Dis. 77:1122-1125.

18. Roelfs, A. P., Long, D. L., and Roberts, J. J. 1995. Races of Puccinia graminis in the United States during 1993. Plant Dis. 79:969972.

19. Roelfs, A. P., Long, D. L., Steffenson, B. J., Jin, Y., Hughes, M. E., and Casper, D. H. 1990. Barley Rusts in the United States in 1990. Barley Newsl. 34:73-76.

20. Roelfs, A. P., and Martens, J. W. 1988. An international system of nomenclature for $P u c$ cinia graminis f. sp. tritici. Phytopathology 78:526-553.

21. Shands, R. G. 1939. Chevron, a barley variety resistant to stem rust and other diseases. Phytopathology 66:667-668.

22. Shands, R. G. 1946. An apparent linkage of resistance to loose smut and stem rust in barley. J. Am. Soc. Agron. 38:690-692.

23. Stakman E. C., and Harrar, J. G. 1957. Principles of Plant Pathology. Ronald Press Co. New York.

24. Steffenson, B. J. 1992. Analysis of durable resistance to stem rust in barley. Euphytica 63:153-167.

25. Steffenson, B. J., Jin, Y., Fetch, T. G., and Miller J. D. 1990. Reaction of five barleys to infection by race QCC of Puccinia graminis $\mathrm{f}$. sp. tritici. Barley Newsl. 34:99-100.

26. Zadoks, J. C., Chang, T. T., and Konzak, C. F. 1994. A decimal code for the growth stages of cereals. Weed Res. 14:415-421.

27. Zubriski, T. C., Vasey, E. H., and Norum, E. B. 1970. Influence of nitrogen and potassium fertilizers and dates of seeding on yield and quality of malting barley. Agron. J. 62:216-219. 